\title{
The level of serum Tumor Marker CA15-3 in women with Breast Cancer \\ Huda Hameed Othman $(\mathrm{MBChB})^{1}$, Walaa Najm Abood $(\mathrm{PhD})^{2}$ and Nazar Abdul Hassan Alwakeel (FICM) ${ }^{3}$
}

\begin{abstract}
Background: Breast cancer is the most frequently diagnosed type of cancer in women in all world regions. About 1.7 million cases of breast cancer are diagnosed every year. Breast cancer is the most common cause of death in women worldwide. There were approximately 0.5 million deaths worldwide from breast cancer in 2012, several serum tumor markers have been evaluated in breast cancer. CA15-3 is the most important serum biomarkers used for diagnosis and monitoring of breast cancer.

Objective: To evaluate the level of CA15-3 of studied groups according to age categories, residence nearby industries, and history of breast feeding.

Patients and Methods: This study was carried out at the Breast Surgery Outpatients and the Oncology Clinic at Oncology Teaching Hospital in Baghdad. It included 50 women who were newly diagnosed by oncology group to have had breast cancer and didn't receive chemotherapy yet and 50 healthy women as control.

Results: There was significant increase at $(\mathrm{P}>0.05)$ in serum CA15-3 level of patients with age category (71-80) years $(198.33 \pm 136.60 \mathrm{U} / \mathrm{ml})$ and significant elevation in serum CA15-3 level of patients who lived near industries or incinerators $(120 \pm 94.52 \mathrm{U} / \mathrm{ml})$ also there was significant increase in serum CA15-3 level in healthy women with breast feeding history $(25.8 \pm$ $15.26 \mathrm{U} / \mathrm{ml})$.

Conclusion: CA15-3 level significantly elevated in elderly patients with age category (7180) years and in patients with residence nearby industries or incinerators. Therefore, those patients at high risk of developing metastatic breast cancer or advanced stages of breast cancer.
\end{abstract}

Key words: Breast Cancer, Tumor Marker, CA15-3.

Corresponding Author: Dr_huda_84@yahoo.com

Received: $28^{\text {th }}$ February 2018

Accepted: $17^{\text {th }}$ April 2018

https://doi.org/10.26505/DJM

${ }^{1,2}$ College of Medicine- Diyala University - Diyala -Iraq.

Introduction

${ }^{3}$ Medical city -BaghdadTeaching Labortaries-Baghdad- Iraq.

Breast cancer is the most frequently diagnosed type of cancer in women in all world regions. About 1.7 million cases are diagnosed every year $[1,2]$. Higher incidence documented in higher income regions (92 per 100,000 in North America) and lower incidence (27 per 100,000 in Middle Africa and Eastern Asia) documented in lower income regions [1, 3, 4]. Breast cancer is the most common cause of death in women worldwide [2]. There were approximately 0.5 million deaths worldwide from breast cancer in 2012 [1]. Breast cancer survival rate being significantly less in low and middle income 
countries compared with high income countries [3].

By routine self-breast examination and mammographic screening breast cancer whether in situ or invasive could be detected [5]. During the early stages of breast cancer swollen and enlarged lymph nodes may be present [3]. It is recommended that all females should follow the current breast cancer screening guidelines to identify those with abnormal breast tissue during the early stages. Breast cancer has many treatment options, which include surgery, chemotherapy, radiation therapy, target therapy and hormonal therapy depending on the stage, as well as on the histological and molecular subtypes [6]. The stage of breast cancer at time of diagnosis is a major determinant of survival from breast cancer. Earlier stage of breast cancer at time of diagnosis was a major contributor to the sharp reductions in breast cancer mortality [7]. Several serum tumor markers have been evaluated in breast cancer. Tumor markers are molecules which undergo important alterations during cancer and carry high clinical significance. Tumor markers may be proteins, nucleic acids, iso-enzymes, metabolites or hormones and are classified as prognostic, predictive and diagnostic [8].

Diagnostic biomarkers are used for the detection of the disease, whereas prognostic biomarkers give information about course of recurrence of the disease. On the other hand, predictive markers are important to evaluate the response to treatment [9]. Cancer-specific detection and identification of these biomarkers could help in early monitoring and diagnosis of disease progression [10]. CA15-3 is the most important serum biomarkers used for diagnosis and monitoring of breast cancer $[11,12]$. CA 153 mostly used in monitoring therapy in advance breast cancer cases [12].

\section{Patients and Methods}

This study was carried out at the Breast Surgery Outpatients and the Oncology Clinic at Oncology Teaching Hospital in Baghdad during the period from September 2016 to March 2017. It included 50 women who were already newly diagnosed by oncology group to have had breast cancer and didn't receive chemotherapy yet, their age range from (3478 years) and 50 healthy women as control, their age range from (34-76 years). The patients and control were classified according to their age into five categories $(31-40 ; 41-$ 50; 51-60; 61-70; 71-80) years old. A pretested questionnaire was filled through direct interview with each studied case. The participants were confirmed as having breast cancer based on physical examination, radiological examination, Fine Needle Aspiration (FNA) and true cut biopsy by histopathology after partial or total mastectomy with axillary clearance. Five milliliters of venous blood was aspirated from patients and control, blood samples were collected in serum separating tubes and left for $15 \mathrm{~min}$ at room temperature for clotting then these tubes were centrifuged for $10 \mathrm{~min}$ at $(2000 \mathrm{x} \mathrm{g})$ and the collected serum shifted to another small plastic labeled tubes and frozen at $-20 \mathrm{oC}$ to be analyzed later for 
tumor markers determination by Enzyme Linked Immuno Sorbent Assay (ELISA), the hemolyzed samples were discarded. Statistical Analysis

The statistical analysis was done by using SPSS version 21 statistical analysis software to analyze the data. The data were presented as mean \pm standard deviation (SD). The statistical examination of data was done through one-way analysis of variance test (ANOVA), Dunnett t-test (comparing the patient groups with control). In addition, $\mathrm{T}$ test was used for the comparison between two groups.

\section{Results}

Figure 1 presents the level of serum CA15-3 among control group with age categories (31$40,41-50,51-60$ and 61-70) years old (19 \pm $4.52 ; 23.5 \pm 9.78 ; 26.30 \pm 16.06 ; 19.33 \pm$ $4.47 \mathrm{U} / \mathrm{ml}$ ) respectively and levels of serum CA15-3 in patients group $(7.75 \pm 3.3 ; 87.38$ $\pm 73.13 ; 77.53 \pm 64.94 ; 102.81 \pm 63.18$ ) among the same age categories respectively. No significant differences at $(\mathrm{P}>0.05)$ were noticed on comparisons between the above age categories levels. The same figure also shows that there was significant increase at (P> 0.05) in serum CA15-3 level of patients with age category (71-80) years old (198.33 $\pm 136.60 \mathrm{U} / \mathrm{ml}$ ) in comparison to control with the same age $(23.5 \pm 2.12 \mathrm{U} / \mathrm{ml})$.

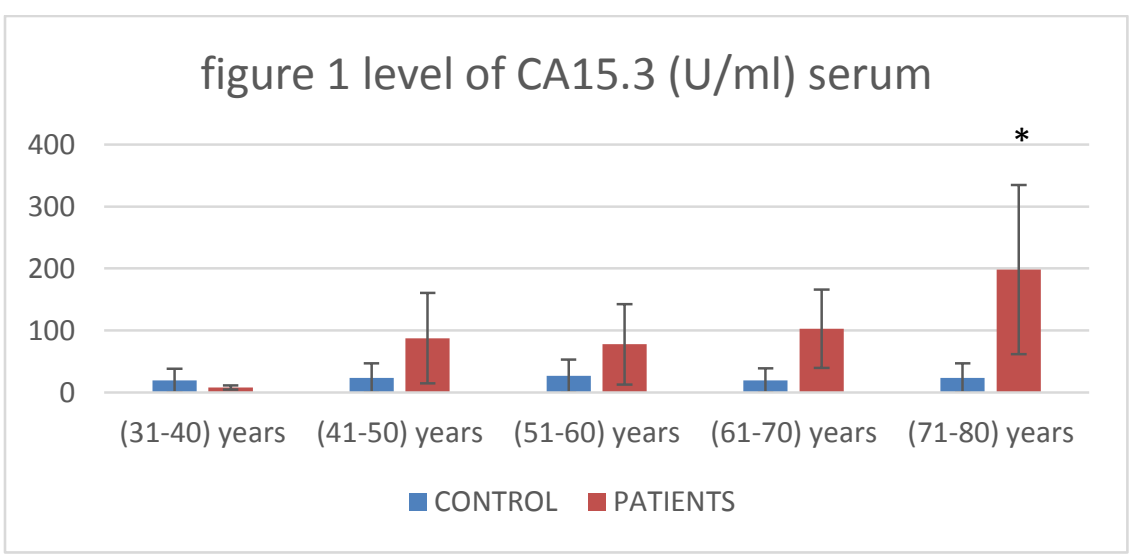

Figure (1): The levels of serum CA15-3 (U/ml) of studied women according to age categories.

Figure (2) shows the level of serum CA153 among control group who lived nearby industries or incinerators $(22.14 \pm 4.71 \mathrm{U} / \mathrm{ml})$ and the level of CA15-3 in the serum of control group who lived away from industries or incinerators $(23.72 \pm 13.01$ $\mathrm{U} / \mathrm{ml})$. The same figure reveals that there was significant increase at $(\mathrm{P}>0.05)$ in the level of CA15-3 in patients who lived near the industries or incinerators $(120 \pm 94.52$ $\mathrm{U} / \mathrm{ml}$ ) while the level of CA15-3 in patients who lived away from industries or incinerators was $(71.34 \pm 56.59 \mathrm{U} / \mathrm{ml})$. 


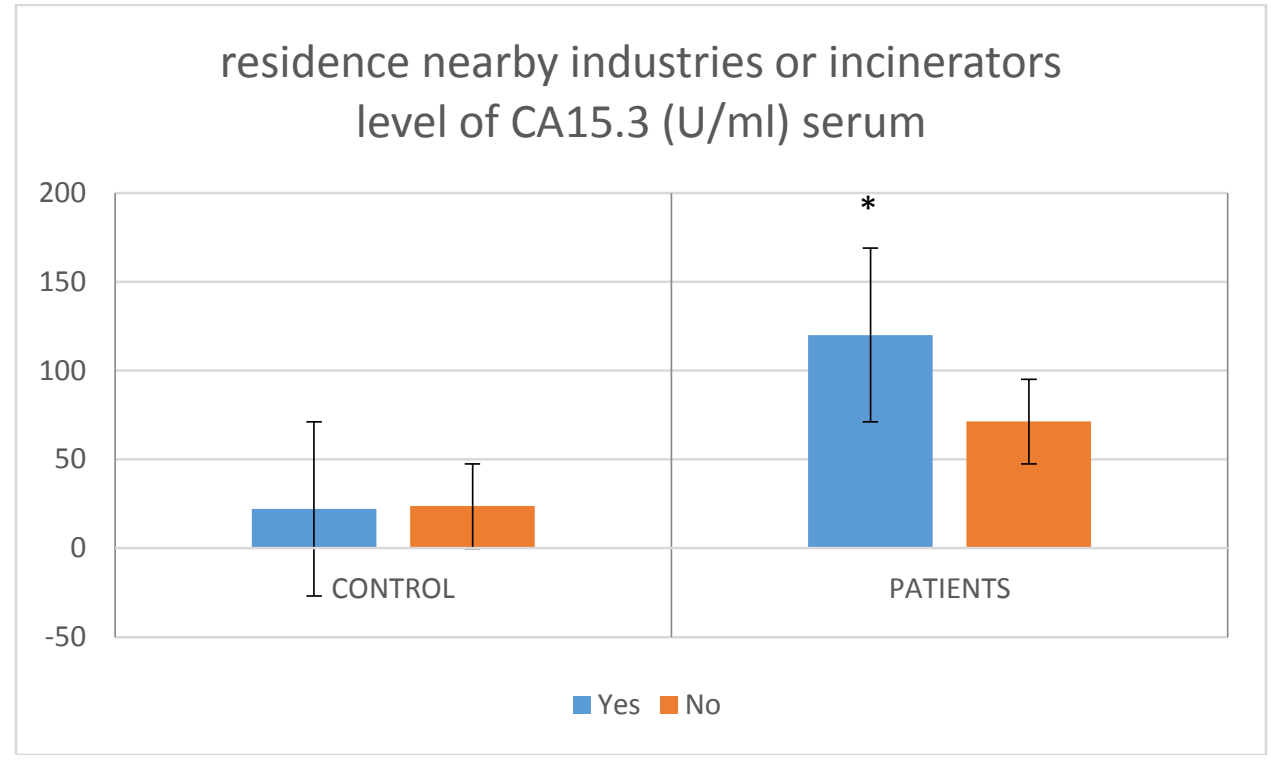

Figure (2) The level of serum CA15-3 (U/ml) according to residence nearby industries or incinerators among studied groups.

Table (1) shows that there was significant increase at $(\mathrm{P}>0.05)$ in the level of CA15-3 of healthy female with breast feeding history $(25.8 \pm 15.26 \mathrm{U} / \mathrm{ml})$, while the level of CA15-3 was $(19.6 \pm 15.26 \mathrm{U} / \mathrm{ml})$ in healthy female with no breast feeding history. Table
(1) also reports that there was no significant difference in the level of CA15-3 between patients with breast feeding history and those with no breast feeding history (57.46 \pm $42.18 ; 102.31 \pm 82.67 \mathrm{U} / \mathrm{ml}$ ) respectively.

Table (1): Level of serum CA15-3 (U/ml) of studied groups according to history of breast feeding.

\begin{tabular}{||c||c||c||c||}
\hline \hline Groups & Tumor markers & History of breast feeding & Mean.SD dev. \\
\hline \hline \multirow{2}{*}{ Control } & $\begin{array}{c}\text { Level of S. CA15-3 } \\
(\mathrm{U} / \mathrm{ml})\end{array}$ & Yes & $25.64 * \pm 14.58$ \\
\cline { 3 - 4 } & Level of S. CA15-3 & No & $20 \pm 5.27$ \\
\cline { 4 - 4 } Patients & \begin{tabular}{c} 
(U/ml) \\
\cline { 3 - 4 }
\end{tabular} & Yes & $57.47 \pm 42.19$ \\
\hline
\end{tabular}

\section{Discussion}

The results of this study reveal that there was significant increase at $(\mathrm{P}<0.05)$ in serum CA15-3 level in patients with age category (71-80) years old. Similar findings were reported by others $[13,14]$. This observation can be explained by the fact that aging will lead to diminished in sialylation and unmasking of MUC-1 antigenic sites which recognized by the assay [13]. The results in figure (2) show that there was significant increase in serum CA15-3 level of breast 
cancer patients who lived in places near industries or incinerators, therefore, they exposed to gases and chemicals related- air pollution. Hystad et al. stated that many of these chemicals or gases compounds are mutagenic and carcinogenic substances which can lead to development of various types of can $\neg$ cer, also they estimated the association between air pollution and breast cancer development and revealed that exposure to air pollution will increase the risk of developing breast cancer and for post-menopausal women the risk increased by $10 \%$ and they explained this association by the fact that chemicals and gases-related air pollution may contribute to breast cancer risk by damaging DNA, promoting tumor growth, or increasing susceptibility by altering how the mammary glands develop [15].

In present study, the results in table (1) show that there was significant elevation in CA15-3 level of healthy control with positive history of breast feeding. The explanation for this result, that healthy control may have another risk factors lead to the elevation of the marker like family history, hormonal replacement therapy, previous exposure to ionizing radiation and other risk factors. Therefore, those women need to follow up by making check up every couple months by retesting the marker and doing additional diagnostic methods like mammography and ultrasound examination.

\section{Conclusion}

In conclusion, serum CA15-3 level significantly elevated in elderly patients with age category (71-80) years and in patients with residence nearby industries or incinerators. Therefore, those patients at high risk of developing metastatic breast cancer or advanced stages of breast cancer.

\section{References}

[1] Ferlay, J.; Soerjomataram, I.; Ervik, M.; Dikshit, R.; Eser, S.; Mathers, C. et al. (2012). Globocan 2012: Estimated Cancer Incidence, Mortality and Prevalence Worldwide in 2012, Iarc Cancer Base. No. 11, V.1.0.

[2] Ferlay, J.; Soerjomataram, I.; Dikshit, R.; Eser, S.; Mathers, C.; and Rebelo, M. (2015). Cancer incidence and mortality worldwide: sources, methods and major patterns, Int $\mathbf{J}$ Cancer. 136(5): E359- 86.

[3] Ginsburg, O.; Bray, F.; Coleman, M.P.; Vanderpuye, V.; Eniu, A. and Kotha, S.R. et al. (2016). The global burden of women's cancers: a grand challenge in global health, Lancet. 389:847-60.

[4] Torre, L.A.; Siegel, R.L.; Ward, E.M.; and Jemal, A. (2016). Global cancer incidence and mortality rates and trends an update, Can Epidemiol Biomarkers Prev. 25(1):16-27.

[5] American Cancer Society (2017). Breast Cancer Facts\& Figures.

[6] National Cancer Institute. (2017). Breast Cancer Screening (PDQ) Health Professional Version.

[7] Allemani, C.; Weir, H.K.; Carreira, H.; Harewood, R.; Spika, D.; Wang, XS. et al. (2015). Global surveillance of cancer survival 1995-2009: analysis of individual data for 25,676,887 patients from 279 
population-based registries in 67 countries, Lancet.14. 385(9972): 977-1010.

[8] Sankara,V.; Jayanthi, .; Das, A.B.; and Saxena, U. (2017). Recent Advances in Biosensor Development for the Detection of Cancer Biomarkers, Biosens Bioelectron. 91(15): 15-23.

[9] Fong, Z.V.; and Winter, J.M. (2012). Biomarkers in Pancreatic Cancer: Diagnostic, Prognostic, and Predictive, Cancer J. 18(6):530-8.

[10] Chatterjee, S.K.; and Zetter, B.R. (2005). Cancer biomarkers: knowing the present and predicting the future, Future Oncol. 1(1): 37-50.

[11] Tothill, I.E. (2009). Biosensors for cancer markers diagnosis, Semin Cell Dev Biol. 20(1): 55-62.

[12] Duffy, M.J. (2006). Serum Tumor Markers in Breast Cancer: Are They of Clinical Value? Clin. Chem. 52(3):345-51.

[13] Rack, B.; Schindlbeck, C.; Jückstock, J.; Genss, E.M.; Hepp, P.; Lorenz, R. et al. (2010). Prevalence of CA 27.29 in primary breast cancer patients before the start of systemic treatment, Anticancer Res. 30 (5):1837-41.

[14] Lumachi, F. (2010). Hormon receptor rate MIB-1 score and serum tumor markers CEA and CA15-3 relationship in elderly women with PT1-2 breast cancer, Anticancer Res. 30(11): 4701-4.

[15] Hystad, P.; Villeneuve, P.J.; Goldberg, M.S.; Crouse, D.L.; and Johnson, K. (2015). Exposure to traffic-related air pollution and the risk of developing breast cancer among women in eight Canadian provinces: A casecontrol study, Environ Int. 74:240-8. 